\title{
Wellness for the Dermatology Resident
}

\author{
Nadine Shabeeb, MD, MPH
}

\section{RESIDENT PEARLS}

- Resident wellness is an important issue affecting resident physicians of all specialties, including dermatology.

- To improve wellness, changes can be made by targeting the following 4 areas of well-being: professional, physical, psychological, and social.
Resident wellness is an essential topic for residents across all medical and surgical specialties. Although dermatology is an outpatientbased specialty with few emergencies, burnout is still prevalent among dermatology residents. Stress related to studying is one of the most common causes, given the academically rigorous nature of dermatology. To treat burnout and to improve resident wellness, changes can be made to target 4 areas of well-being: professional, physical, psychological, and social.

Cutis. 2020;106:E18-E20.

$\longrightarrow$ esident wellness is a topic that has become increasingly important in recent years due to physician burnout. A prior Cutis Resident Corner column discussed the prevalence of physician burnout and how it can affect dermatologists. ${ }^{1}$ When discussing resident burnout, dermatology may not be a specialty that immediately comes to mind, considering that dermatology is mostly outpatient based, with few emergencies and critically ill patients. In a JAMA study assessing levels of burnout by specialty, dermatology residents were the lowest at

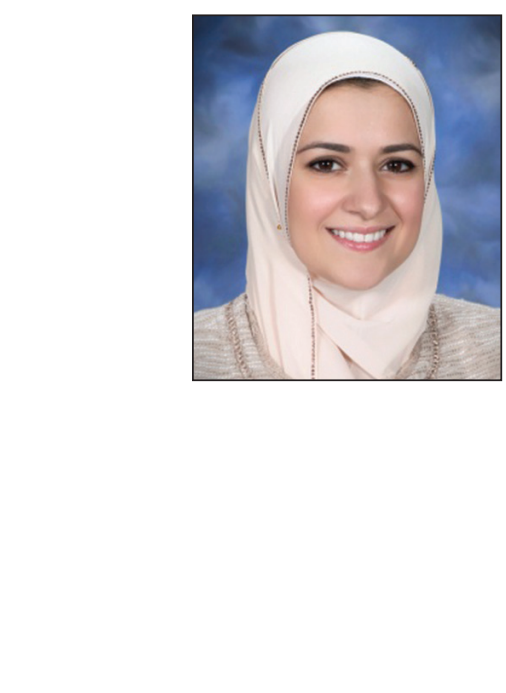

approximately $30 \% .^{2}$ However, this still means that 3 out of every 10 dermatology residents feel burnt out.

\section{BURNOUT IN DERMATOLOGY}

In 2017, results from a survey of 112 dermatology residents in Canada about burnout was published in the British Journal of Dermatology. ${ }^{3}$ The numbers were staggering; the results showed that more than $50 \%$ of dermatology residents experienced high levels of emotional exhaustion and depersonalization, and $40 \%$ had low levels of personal accomplishment. Additionally, 52\% experienced low or depressed mood, $20 \%$ reported feelings of hurting themselves within the last year, and more than 25\% had high anxiety levels. ${ }^{3}$

Dermatology requires a high level of daily studying, which is a major source of stress for many dermatology residents. The survey of dermatology residents in Canada showed that the top stressor for $61 \%$ of survey respondents was studying, specifically for the board examination. ${ }^{3}$ Dermatology is an academically rigorous specialty. We are responsible for recognizing every disease process affecting the skin, including hundreds that are extremely uncommon. We must understand these disease processes at a molecular level from a basic science standpoint and at a microscopic level through our knowledge of dermatopathology. Much of what we see in clinic are bread-and-butter dermatologic conditions that do not necessarily correlate with the rare diseases that we study. This differs from other specialties in which residents learn much of their specialty knowledge through their clinical work.

From the Department of Dermatology, University of Wisconsin Hospital and Clinics, Madison.

The author reports no conflict of interest.

Correspondence: Nadine Shabeeb, MD, MPH, One S Park, 7th Floor, Madison, WI 53715 (nshabeeb@uwhealth.org).

doi: 10.12788 /cutis.0043 


\section{CURRENT CHALLENGES}

We are training in a uniquely challenging time, providing care for our patients amid the coronavirus disease 2019 pandemic. Many of us are dealing with constant levels of stress and worry about the health and safety of ourselves, along with our friends, families, and patients. Some residents have been redeployed to work in unfamiliar roles in the emergency department or hospital wards, while others adjust to new roles in teledermatology. I also cannot talk about resident wellness without recognizing the challenges faced by physicians who are racial and religious minorities. This is especially true for black physicians, as they face unconscious biases and microaggressions daily derived from implicit racism; this leads to discrimination in every area of life and ultimately harms their emotional and psychological well-being. ${ }^{4}$ Additionally, black physicians are underrepresented in dermatology, making up only $4.3 \%$ of dermatology residents in the 2013-2014 academic year. ${ }^{5,6}$ Underrepresentation can serve as a major stressor for racial and religious minorities and should be considered when addressing resident wellness to ensure their voices are heard and validated.

\section{FOCUSING ON WELLNESS}

What can we do to improve wellness? A viewpoint published in JAMA Surgery in 2015 by Salles et $\mathrm{al}^{7}$ from the Stanford University Department of Surgery (Stanford, California) discussed their Balance in Life (BIL) program, which was established after one of their residency graduates tragically died by suicide shortly after graduating from residency. The BIL program addresses 4 different facets of well-being-professional, physical, psychological, and social-and lists the specific actions taken to improve these areas of well-being. ${ }^{7}$

I completed my transitional year residency at St. Vincent Hospital (Indianapolis, Indiana). The program emphasizes the importance of resident wellness. They established a department-sponsored well-being program to improve resident wellness, ${ }^{8}$ with its objectives aligning with the 4 areas of well-being that were outlined in the Stanford viewpoint. ${ }^{7}$ A short Q\&A with me was published in the supplemental material as a way of highlighting their residents. ${ }^{9}$ I will outline the 4 areas of well-being, with suggestions based on the Stanford BIL program, the well-being innovation program at St. Vincent, and initiatives at my current dermatology residency program at the University of Wisconsin (UW) in Madison.

\section{THE 4 AREAS OF WELL-BEING Professional Well-being}

Stanford BIL Program-One of the changes implemented was starting a resident mentorship program. Each junior resident selects a senior resident as a mentor with department-sponsored quarterly lunch meetings. ${ }^{7}$ Another initiative is a leadership training program, which includes an outdoor rope course each year focusing on leadership and team building. ${ }^{7}$
UW Dermatology — Monthly meetings are held with our program director and coordinator so that we can address any concerns or issues as they arise and brainstorm solutions together. During the coronavirus disease 2019 pandemic, we had weekly resident town halls with department leadership with transparency about our institution's current status.

\section{Physical Well-being}

Stanford BIL Program -One method of improving physical well-being included stocking healthy snacks for residents and providing incoming residents with a guide of physicians, dentists, and fitness venues to promote regular health care. We have adopted the same at UW with healthy snacks available in our resident workroom.

St. Vincent Internal Medicine Wellness-There are monthly fitness challenges for a variety of physical wellness activities such as sleep, mindfulness minutes, nutrition, and step challenges. ${ }^{8}$

UW Dermatology - In addition to healthy snacks in our workroom, we also have various discounted fitness classes available for employees, along with discounts on gym memberships, kayak rentals, and city bike-share programs.

\section{Psychological Well-Being}

Stanford BIL Program-They enlisted a clinical psychologist available for residents to talk to regularly about any issues they face and to help manage stress in their lives. ${ }^{7}$

St. Vincent Internal Medicine Wellness-Faculty and coordinators provide S.A.F.E.—secure, affirming, friendly, and empathetic - zones to provide confidential and judgment-free support for residents. ${ }^{8}$ They also host photography competitions; residents submit photographs of nature, and the winning photographs are printed and displayed throughout the work area.

UW Dermatology - We have made changes to beautify our resident workroom with photograph collages of residents and other assorted décor to make it a more work-friendly space.

\section{Social Well-being}

Common themes highlighted by all 3 programs include the importance of socializing outside of the workplace, team-building activities, and resident retreats. Social media accounts on Instagram at St.Vincent (@stvimresidency) and at UW (@uwderm) highlight resident accomplishments and promote interconnectedness when residents are not together in clinics or hospitals.

\section{FINAL THOUGHTS}

Resident wellness will continue to be an important topic for discussion in the future, especially given the uncertain times right now during our training. Focusing on the 4 areas of well-being can help to prevent burnout and improve resident wellness.

\section{REFERENCES}

1. Croley JAA. \#Dermlife and the burned-out resident. Cutis. 2019; 104:E32-E33. 
2. Dyrbye LN, Burke SE, Hardeman RR, et al. Association of clinical specialty with symptoms of burnout and career choice regret among US resident physicians. JAMA. 2018;320:1114-1130.

3. Shoimer I, Patten S, Mydlarski PR. Burnout in dermatology residents: a Canadian perspective [published online November 1, 2017]. Br J Dermatol. 2018;178:270-271.

4. Grills CN, Aird EG, Rowe D. Breathe, baby, breathe: clearing the way for the emotional emancipation of black people. Cultural Studies \& Critical Methodologies. 2016;16:333-343.

5. Imadojemu S, James WD. Increasing African American representation in dermatology. JAMA Dermatol. 2016;152:15-16.
6. Brotherton SE, Etzel SI. Graduate medical education, 2013-2014. JAMA. 2014;312:2427-2445.

7. Salles A, Liebert CA, Greco RS. Promoting balance in the lives of resident physicians: a call to action. JAMA Surg. 2015;150:607-608.

8. Fick L, Axon $\mathrm{K}$, Potini $\mathrm{Y}$, et al. Improving overall resident and faculty wellbeing through program-sponsored innovations. MedEdPublish. Published September 27, 2019. doi:10.15694/mep.2019.000184.1.

9. St. Vincent Internal Medicine Residency Wellness Bulletin. https://www.mededpublish.org/manuscriptfiles/2586 /Supplementary\%20File\%203_Wellness\%20Bulletin.pdf. Published April 2018. Accessed August 5, 2020. 